\title{
Incidence and risk of hypertension associated with vascular endothelial growth factor receptor tyrosine kinase inhibitors in cancer patients: a comprehensive network meta-analysis of 72 randomized controlled trials involving 30013 patients
}

\author{
Bo Liu ${ }^{1,3}$, Fengxia Ding ${ }^{2,3}$, Yang Liu1,3, Geng Xiong ${ }^{1,4}$, Tao Lin ${ }^{1}$, Dawei He ${ }^{1}$, Yuanyuan \\ Zhang ${ }^{4}$, Deying Zhang ${ }^{1,3}$ and Guanghui Wei ${ }^{1}$ \\ 1 Department of Urology, Children's Hospital of Chongqing Medical University, Chongqing, China \\ 2 Department of Respiratory Medicine, Children's Hospital of Chongqing Medical University, Chongqing, China \\ 3 Ministry of Education Key Laboratory of Child Development and Disorders, Chongqing Key Laboratory of Pediatrics, \\ Chongqing International Science and Technology Cooperation Center for Child Development and Disorders, Chongqing, \\ China \\ ${ }^{4}$ Wake Forest Institute for Regenerative Medicine, Wake Forest School of Medicine, Winston-Salem, NC, USA \\ Correspondence to: Deying Zhang, email: DeyingZhang@126.com \\ Guanghui Wei, email: Guanghuiweicqmu@126.com
}

Keywords: meta-analysis, cancer, VEGFR-TKIs, hypertensive events

Received: April 28, $2016 \quad$ Accepted: August 23, $2016 \quad$ Published: September 01, 2016

ABSTRACT

Background: Tyrosine kinase inhibitors (TKIs) have been developed during the last decade that target the vascular endothelial growth factor receptor (VEGFR) are currently being evaluated as treatments for malignant tumors. The increased application of VEGFR-TKIs means that the probability of hypertension is a serious concern. However, the reported incidence varies markedly between clinical trials. Here, we undertook an up-to-date, comprehensive meta-analysis on clinical works to build the incidence of hypertension along with VEGFR-TKIs. The goal was to understand better of the overall venture of cancer patients' hypertension treated with these drugs.

Methods: Databases (EMBASE, PubMed, and Cochrane library) and the abstracts of the American Society of Clinical Oncology annual meeting and European Society of Medical Oncology were searched to identify related studies. $95 \%$ confidence intervals (CIs), summary incidences, and relative risk (RR) were calculated utilizing either fixed-effects models on the basis of the heterogeneity of the included studies or random-effects.

Results: Seventy-two randomized controlled trials (including 30013 patients) were involved. The total incidence of high-grade and all-grade hypertensive events along with VEGFR-TKIs was $23.0 \%$ (95\% CI, $20.1-26.0 \%)$ and $4.4 \%(95 \%$ CI, 3.7-5.0\%), respectively. The use of VEGFR-TKIs remarkably enhanced the venture of developing high-grade ( $R R, 4.60 ; 95 \% C I, 3.92-5.40 ; P<0.001)$ and all-grade (RR, 3.85; 95\% CI, 3.37-4.40; $P<0.001$ ) hypertensive events. Subgroup analyses revealed that the risk of a hypertensive event varied significantly in accordance with tumor type, VEGFR-TKI, trial phase, VEGFR-TKIs-based regimen, control therapy, and chemotherapy regimen.

Conclusions: Patients with cancer that receive VEGFR-TKIs are at a remarkable venture of developing hypertension. Therefore, suitable treatment and monitoring should be introduced to avoid cardiovascular complications. 


\section{INTRODUCTION}

Malignant tumors are one of the most serious diseases threatening human life and for which systematic chemotherapeutics are still the main treatment of choice [1]. Because such treatments often fail due to the development of multidrug-resistant tumor cells, targeted therapies may be the best route forward [2]. Research and clinical practice show that vascular epithelial growth factor (VEGF) is very important for tumor growth, progression, and metastasis because it induces angiogenesis [3, 4]. Blockade of the VEGF signaling pathway is an important goal for those developing anticancer drugs [5]. Anti-VEGF monoclonal antibodies (e.g., bevacizumab) [6], anti-VEGF receptor (R)-2 antibodies (e.g., ramucirumab) [7], VEGF-ligand-binding fusion proteins (e.g., aflibercept) [8], and VEGFR-TKIs known as vascular epithelial growth factor receptor tyrosine kinase inhibitors (e.g., cabozantinib), the numerous angiogenesis inhibitors, have shown promising clinical efficacy against various malignant diseases and have been approved by the European Medicines Agency and the United States FDA [9].

Although VEGFR-TKIs are considered more specific and less toxic than conventional chemotherapy, severe side effects such as congestive heart failure and cerebrovascular events are particular concerns [10]. One major side effect noted in numerous trials is the onset of hypertension, the incidence of which ranges from $16.0-42.6 \%$ [11]. Adequate and aggressive treatment of hypertension is a significant issue for patients treated with VEGFR-TKIs due to the fact that serious kidney and cardiovascular diseases are caused by poorly controlled hypertension. Also, the usage of VEGF-TKIs could be linked to posterior reversible encephalopathy syndrome, which is a clinico-radiological event that includes symptoms such as headaches, nausea and emesis, visual loss and seizures, and particularly acute hypertension [12]. Not enough post-marketing experience, underreporting, diagnosis difficulties, and bad follow-upping of exposed patients signify that the total risk and incidence of hypertension related to VEGFR-TKIs are uncertain. Thus, we performed this meta-analysis to examine the issue.

\section{RESULTS}

\section{Systematic literature search}

The study was carried out according to the Systematic Review and Meta-analyses statement (Supplementary Table S2) [16]. For the meta-analysis, 1870 abstracts reported the usage of VEGFR-TKIs and 72 RCTs were comprised in total. Overall, 30013 patients

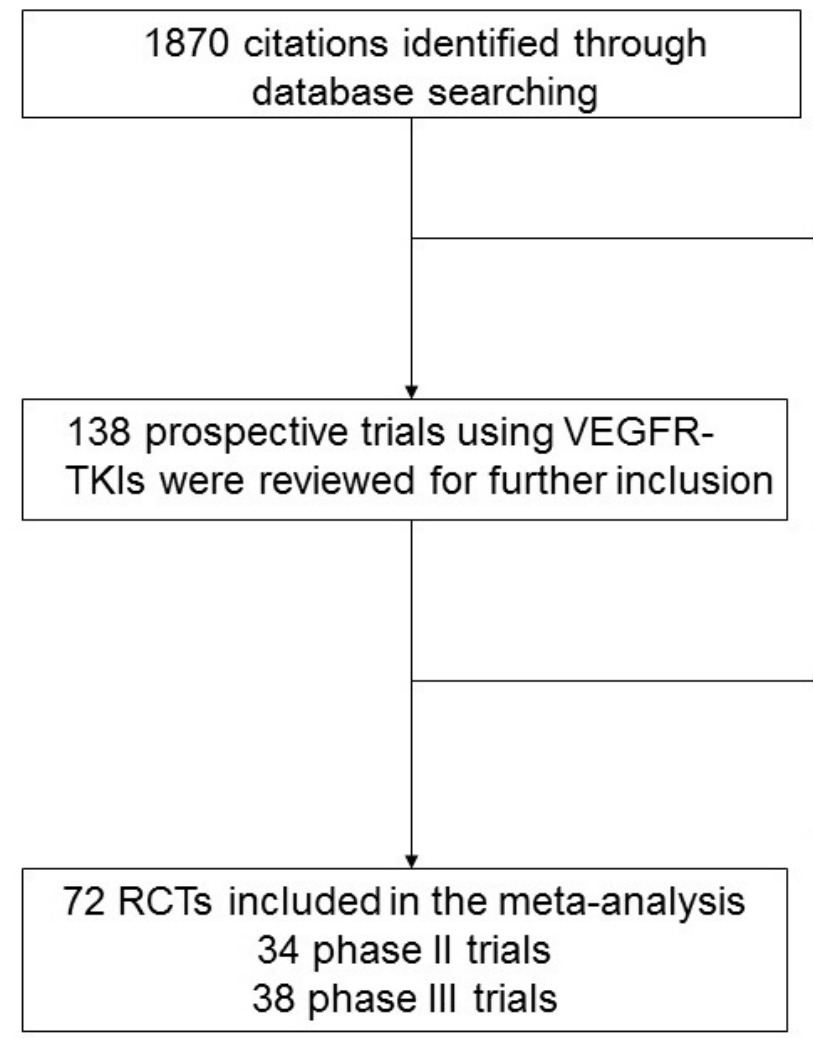

\section{2 articles excluded: Phase I trials, duplicated articles, review articles, commentaries or letters, case report, retrospective study or not neoplastic disease publications}

\section{Excluded \\ 35 Single arm phase II trials \\ 8 VEGFR-TKIs in both treatment and control arms \\ 23 Data not adequate for evaluation of hypertensive events}

Figure 1: Selection process for randomized controlled trials included in the meta-analysis. 
were randomly assigned to either VEGFR-TKI-treated or control groups according to each individual trial eligibility criteria. The main criteria comprised of an Eastern Cooperative Oncology Group performance indicator of 0 or 1 , adequate hematologic, cardiac, and kidney function, and a variety of cancers. Figure 1 describes the overall descriptive selection criteria. The attributes of the 72 incorporated trials was great [mean score, 4 (range, 3-5)]. Jadad scores of five were found thirty-five trials. Another 37 experiments did not describe the method for blinding and (or) randomization legibly; thus these trials were given scores of 3 or 4 on the Jadad scale. The patient and study attributes for all comprised trials are shown in Supplementary Table S3.

\section{Incidence of all-grade hypertensive events}

The analysis contained 12736 patients treated with VEGFR-TKIs in 64 RCTs, 2972 of whom experienced hypertensive events. A renal cell Phase II trial carcinoma showed the highest overall incidence $(64.2 \% ; 95 \% \mathrm{CI}$, $51.2-77.1 \%$ ) [54]; the three trials with the lowest incidence did not report any all-grade hypertensive events $[33,75$, 85]. A random-effects model $\left(\mathrm{c}^{2}\right.$-based Q-statistic test: $\mathrm{q}$ $\left.=3727.72 ; P<0.001 ; I^{2}=98.3 \%\right)$ revealed that the total occurrence of all-grade hypertensive occasions in cancer patients treated with VEGFR-TKIs was 23.0\% (95\% CI, 20.1-26.0\%, Supplementary Table 4 and Figure S1).

\section{Incidence of high-grade hypertensive events}

The analysis contained 15975 patients treated with VEGFR-TKIs in 71 RCTs; 1023 patients experienced high-grade hypertensive events. The highest occurrence (30.8\%; 95\% CI, 26.7-35.0\%) was seen in a Phase III trial for ovarian cancer [69], whereas the lowest overall incidence was detected in ten trials that reported no sign of high-grade hypertensive events $[27,33,36,46,56,62,63$, $75,78,85]$. A random-effects model ( $\mathrm{c}^{2}$-based Q-statistic test: $\left.\mathrm{q}=1065.86 ; P<0.001 ; I^{2}=93.4 \%\right)$ revealed that the total occurrence of all-grade hypertensive occasions in cancer patients treated with VEGFR-TKIs was 4.4\% (3.7$5.0 \%$, 95\% CI, Supplementary Table 4 and Figure S2).

\section{RR of hypertensive events}

23511 patients in 64 RCTs were incorporated when computing the RR of all-grade hypertensive events. The venture of all-grade hypertension occasions increased dramatically after treatment with VEGFR-TKIs: a random-effects model $\left(I^{2}=44.1, P<0.001\right)$ yielded an RR of 3.85 (95\% CI, 3.37-4.40; $P<0.001$; Supplementary Table 4 and Figure S3). We also examined the stability and reliability of the combined results using a sensitivity analysis. The results showed that leaving any single trial out did not affect the significance estimate for the pooled RRs (Supplementary Figure S5 and Figure S6). Moreover, we conducted a meta-regression analysis to examine if different treatment times affected the RR of hypertensive events. Since 18 studies reported no data on the duration of the treatment, only 46 of the 64 studies were incorporated in the overall analysis. The results showed that different treatment times were not a source of heterogeneity $(P=$ 0.896). High-grade hypertensive events occurred in a total of 29085 patients in 71 RCTs. The pooled RR derived from a fixed-effects model $(I 2=0 \%, P=0.941)$ revealed

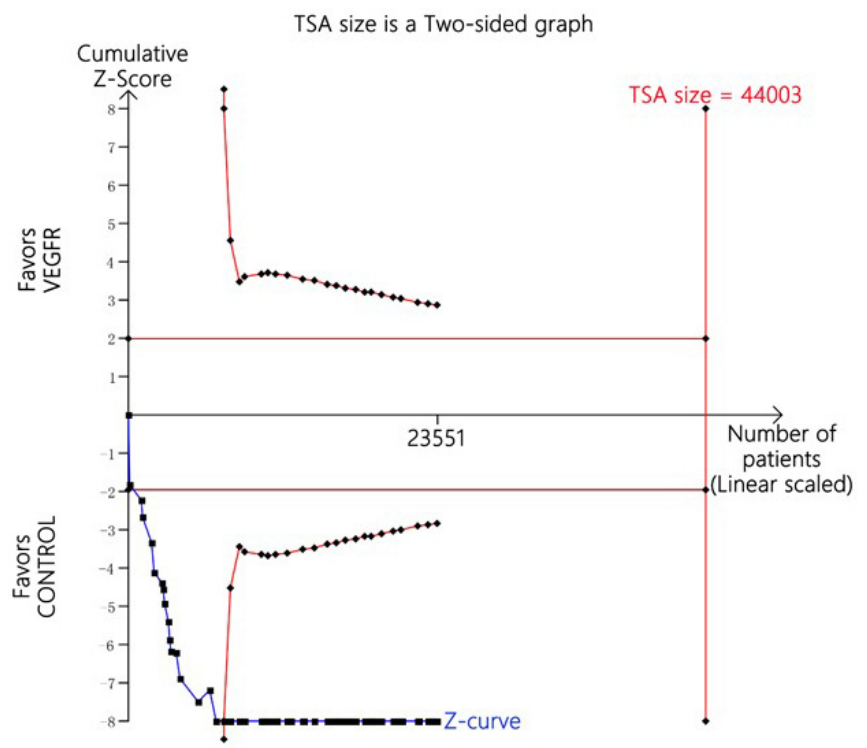

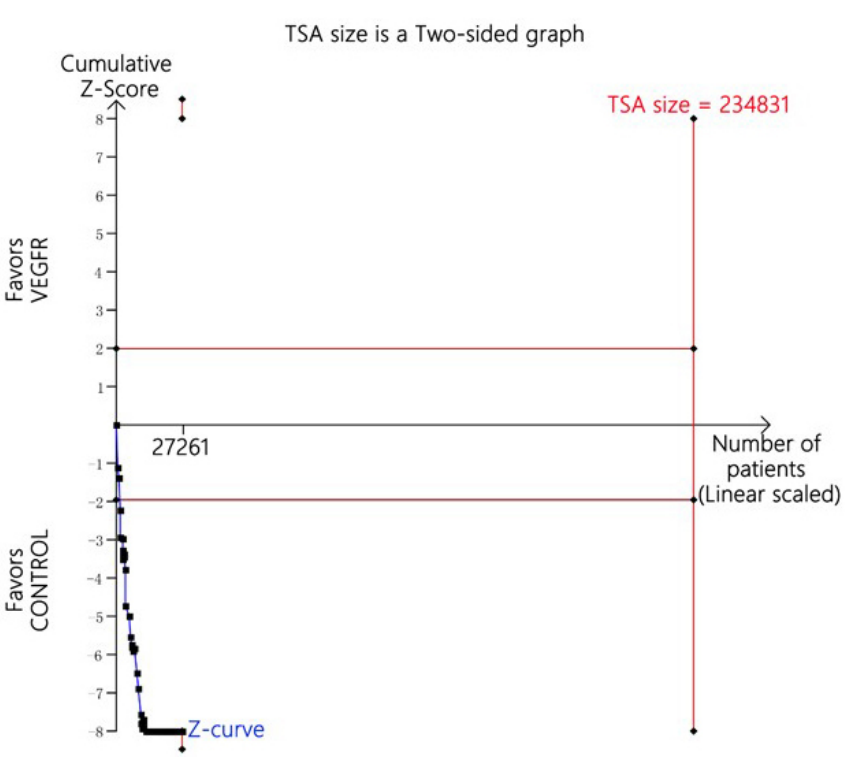

Figure 2: Trial sequential analysis of trials with a lower risk of bias when reporting hypertensive events. 
that the danger of high-grade hypertensive incidents among patients of cancer was significantly higher after treatment with VEGFR-TKIs (RR, 4.60, 95\% CI, 3.925.40; $P<0.001$; Supplementary Table 4 and Figure S4).

\section{Risk of hypertensive events on basis of tumor type, VEGFR-TKI, trial phase, chemotherapy condition, treatment regimen, and control therapy}

We next examined the RR of VEGFR-TKIassociated hypertensive events with regard to the classified tumor type. The largest RR of all-grade hypertensive occasions was found in individuals with breast cancer (95\% CI, 2.96-12.79; RR, 6.15), while the smallest RR was detected in individuals with gastric cancer $(95 \% \mathrm{CI}$, 0.02-43.40; RR, 0.88). Moreover, a markedly increasing danger of all-grade hypertensive occasions was detected in patients of $\mathrm{HCC}(\mathrm{RR}, 3.04 ; 95 \% \mathrm{CI}, 2.36-3.92), \mathrm{RCC}$ (RR, 5.55; 95\% CI, 2.75-11.19), thyroid cancer (RR, 4.61; 95\% CI, 3.34-6.38), pancreatic cancer (RR, 3.22; 95\% CI, 2.21-4.69), mCRC (RR, 4.05; 95\% CI, 3.16-5.20), ovarian cancer (RR, 4.65; 95\% CI, 2.30-9.42), GIST (RR, 2.93; 95\% CI, 1.82-4.72), STS (RR, 5.38; 95\% CI, 3.01-9.64), SCLC (RR, 2.38; 95\% CI, 1.20-4.70), PENT (RR, 5.43; 95\% CI, 1.96-15.08), and AML (RR, 2.21; 95\% CI, 1.214.70). With respect to high-grade hypertensive events, the largest RR occurred in individuals with prostate cancer (RR, 8.85; 95\% CI, 1.59-49.12), while the smallest was then detected in individuals with gastric cancer ( RR, 0.88; $95 \%$ CI, 0.02-43.40). However, it was of interest to note that the danger of all-grade hypertensive events decreased non-significantly in patients with R/M HSNCC (RR, 0.94; 95\% CI, 0.02-44.33) or gastric cancer (RR, 0.88; 95\% CI, 0.02-43.40) treated with VEGFR-TKIs, and that the danger of high-grade hypertensive events decreased nonsignificantly in individuals with gastric cancer (RR, 0.88 ; 95\% CI, 0.02-43.40). The RR of high-grade and all-grade

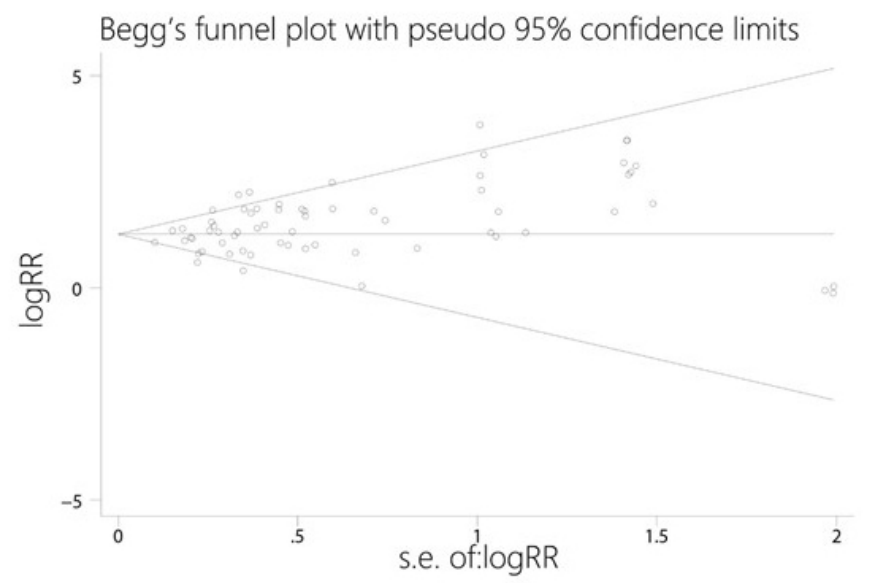

cases are various significantly according to tumor type ( $P$ $<0.001)$, indicating that the probability of all-grade and high-grade hypertensive events after treatment of VEGFR varied in patients with different tumors.

The RR of hypertensive events caused by VEGFRTKIs might be different. The largest RR of all-grade hypertensive events was detected in individuals treated with axitinib (RR, 9.17; 95\% CI, 0.72-116.54), although it is not significantly different in this increased risk, while the smallest RR was detected in individuals treated with sorafenib (RR, 3.07; 95\% CI, 2.43-3.87). The combined results also demonstrated that vandetanib (RR, 5.25; 95\% CI, 4.12-6.70), sunitinib (RR, 7.91; 95\% CI, 5.40-11.57), pazopanib (RR, 7.58; 95\% CI, 3.08-18.62), cediranib (RR, $3.72 ; 95 \%$ CI, 2.95-4.70), regorafenib (RR, 3.96; 95\% CI, 2.72-5.79), motesanib (RR, 4.02; 95\% CI, 2.83-5.70), and cabozantinib (RR, 7.13; 95\% CI, 2.97-17.15) led to a substantial increase in the risk of all-grade hypertensive events. With respect to high-grade hypertensive events, the highest RR was detected in patients receiving cabozantinib (RR, 9.17; 95\% CI, 1.24-67.77), while the smallest was detected in individuals receiving motesanib (RR, 1.01; $95 \% \mathrm{CI}, 0.02-50.87)$. A remarkably increasing risk was detected as well in those taking sorafenib (RR, 3.66; 95\% CI, 2.89-4.63), vandetanib (RR, 5.85; 95\% CI, 3.36-10.20), sunitinib (RR, 4.35; 95\% CI, 3.12-6.07), pazopanib (RR, 5.06; 95\% CI, 3.55-7.22), cediranib (RR, 6.13; 95\% CI, 3.43-10.97), axitinib (RR, 4.22; 95\% CI, 1.75-10.16), and regorafenib (RR, 7.81; 95\% CI, 3.0619.94). The RR of high-grade and all-grade hypertensive cases varied significantly according to the type of VEGFRTKI $(P<0.001)$; thus the risk of high-grade and all-grade hypertensive events probably differs according to the VEGFR-TKI prescribed.

Next, we executed a subgroup examination of the trial phase. The data manifested that the RR of all-grade hypertensive events for Phase II trials was 3.43 (95\% CI, 2.66-4.42) versus 4.06 (95\% CI, 3.48-4.74) for Phase III

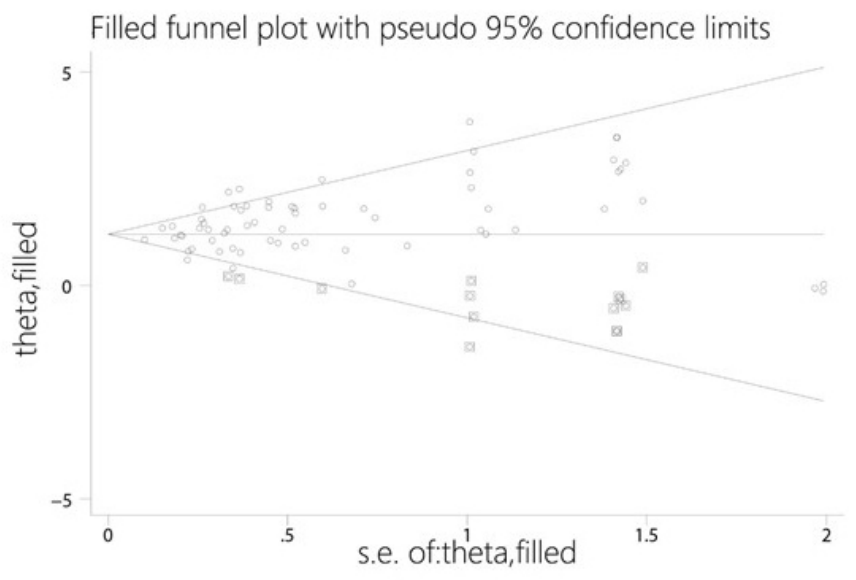

Figure 3: Funnel plots without and with trim and fill. 
trials, whereas the RR of high-grade hypertensive events for Phase II trials was 3.28 (95\% CI, 2.31-4.66) versus 4.97 (95\% CI, 4.14-5.96) for Phase III trials. This diversity between the risk of high-grade and all-grade hypertensive events at different test phases was statistically significant $(P<0.001)$. We also conducted a subgroup examination stratified based on a chemotherapy regimen. The results manifested the RR of all-grade hypertensive events for chemotherapy-naïve patients was 3.33 (95\% CI, 2.823.94) whereas that for pre-chemotherapy was $4.36(95 \%$ CI, 3.57-5.33). The RR of high-grade hypertensive events for chemotherapy-naïve patients was $3.87(95 \%$ CI, 3.12-4.81) versus 5.61 (95\% CI, 4.40-7.16) for prechemotherapy patients. This diersity between the risk of high-grade and all-grade hypertensive events according to chemotherapy conditions was statistically significant $(P<0.001)$. Next, we conducted a subgroup investigation based on the VEGFR-TKI-based regimen. The all-grade hypertensive occurrences in patients received VEGFRTKI monotherapy RR was 4.49 (95\% CI, 3.74-5.39) versus 3.24 (95\% CI, 2.70-3.88) for those receiving combination therapy. Meanwhile, the RR of high-grade hypertensive occurrences for those receiving VEGFR-TKI monotherapy was 5.29 (95\% CI, 4.30-6.51) versus 3.80 (95\% CI, 2.964.88). The difference between the danger of high-grade and all-grade hypertensive occurrences according to VEGF-TKI regimen was statistically significant $(P<$ 0.001). Finally, we performed subgroup analysis based on control therapy. The pooled analysis demonstrated that treatment with a VEGFR-TKI was accompanied by a much higher risk of all-grade hypertensive cases than the placebo (RR, 4.16; 95\% CI, 3.47-4.98) or non-placebo (RR, 3.63; 95\% CI, 2.98-4.41) therapy. In addition, our analysis revealed a large increase in the risk of high-grade hypertensive events when patients received VEGFR-TKIs rather than placebo (RR, 5.13; 95\% CI, 4.13-6.38) or nonplacebo (RR, 3.81; 95\% CI, 3.01-4.83) therapy. These differences were statistically significant $(P<0.001)$.

We used TSA to ensure that suitable sample sizes were included to make sure that the results were not influenced by newly published research, although the cumulative information size did not reach the satisfied information volum; however, the cumulative Z-curve crossed the cut-off level, so we concluded that no additional trials were needed (Figure 2).

\section{Publication bias}

Funnel plots and Egger's tests detected clear publication bias with respect to the RR of the all-grade hypertensive events $(P<0.001)$. So, we adopted an iterative method to evaluate the number of deficient studies (Trim and fill method) and then performed a new meta-analysis after adding in some hypothetical trials [88]. The results still showed a statistically significant relationship between the use of VEGFR-TKIs and all- grade hypertension (95\% CI, 3.00-3.97; RR, 3.45), indicating that the results are unlikely to be affected by publication bias (Figure 3). Egger's tests revealed no significant publication bias with respect to the RR of highgrade hypertensive events $(P=0.312)$. With the trim and fill method, the result also showed a significant association between use of VEGFR-TKIs and hypertension (RR, 4.13; 95\% CI, 3.51-4.87).

\section{DISCUSSION}

VEGF is very important for tumor growth, progression, and metastasis because it induces angiogenesis $[3,4]$. During the last century, Folkman proposed that new blood vessel formation or neovascularization may be a new paradigm for tumorigenesis $[89,90]$. Since then, several anti-angiogenesis drugs that inhibit angiogenesis and malignancy have been ratified for usage as agents to aid with cancer therapy[25, 26, 53, 58, 74]. However, extensive clinical trials of angiogenesis inhibitors used to treat cancer revealed that these inhibitors have unexpected side effects and that hypertensive events are one of the most common. Another meta-analysis indicated that the incidence of hypertension among patients receiving bevacizumab (an anti-VEGF antibody) was $8 \%(95 \% \mathrm{CI}, 6-10 \%)$, and that the danger for the onset of hypertension in individuals treated with bevacizumab increased significantly (RR, 5.38; 95\% CI, 3.63-7.97) [91]. Nevertheless, it is unclear if the usage of VEGFR-TKIs that target VEGF signaling pathways increases the chance for the onset of hypertension in cancer patients.

We believe that this review is one of the first and largest meta-analysis to assess the relationship between hypertension and VEGFR-TKIs. We attempted to examine the risk of hypertension during treatment with various TKIs using CTCAE 2.0 or 3.0. The collective occurrence of VEGFR-TKI-associated high-grade and all-grade hypertensive cases was $23.0 \%$ (95\% CI, 20.1-26.0\%) and $4.4 \%$ (95\% CI, 3.7-5.0\%), respectively, which is lower than that formerly published by Wu (all-grade, 23.4\%; high-grade, 5.7\%) [92]. One possible explanation for this discrepancy is a difference in the tumor type distribution: the major type of cancer examined by Wu was RCC (about $44.4 \%$ of cases), whereas RCC accounted for only $6.3 \%$ of the cases in the present study. Also, Wu examined a small number of RCTs (only four trials). Therefore, the collective study might have been altered by the results of a single large RCT. We also found that VEGFRTKIs caused a significant increase in the probability of all-grade hypertensive events (RR, 3.85; 95\% CI, 3.374.40; $P<0.001)$ and high-grade hypertensive events (RR, $4.60 ; 95 \%$ CI, 3.92-5.40; $P<0.001)$. It was indicated by sensitivity analysis that leaving out any single trial had an insignificant effect on the collective all-grade and high-grade RRs. Based on these results, we concluded that VEGFR-TKIs dramatically enhance the occurrence 
of hypertension in patients of cancer and that intensive monitoring for VEGFR-TKI-associated hypertensive events is suggested throughout the management of hypertension. Furthermore, VEGFR-TKIs appear to increase the risk of renal and cardiovascular events. Appropriate monitoring and management of blood pressure (BP) are expected to reduce both mortality and morbidity due to renal insufficiency, congestive heart failure, stroke, and myocardial infarction, and may prevent patients from abandoning treatment [93].

Additionally, we explored the factors that might lead to risk for VEGFR-TKI-associated hypertensive events. We found that the risk of hypertensive events related to VEGFR-TKIs varies mainly based on tumor type. This finding could be due to the fact that different malignancies have different pathogeneses and different spectra of patient comorbidities. Patients with different tumor types that were treated with VEGFR-TKIs were at a high risk of hypertensive events; the two exceptions were R/M HNSCC and gastric cancer. A possible explanation for this is that the control therapies used in these two cases, cetuximab and docetaxel, are also related with an increased chance of hypertension [94, 95]. This may reduce the RR of VEGFR-TKI-associated hypertension. The occurrence of hypertension connected to different VEGFR-TKIs was also examined, and the results showed that sunitinib (RR, 7.91; 95\% CI, 5.40-11.57), pazopanib (RR, 7.58; 95\% CI, 3.08-18.62), cabozantinib (RR, 7.13; 95\% CI, 2.97-17.15), vandetanib (RR, 5.25; 95\% CI, 4.12-6.70), motesanib (RR, 4.02; 95\% CI, 2.83-5.70), regorafenib (RR, 3.96; 95\% CI, 2.72-5.79), cediranib (RR, 3.72; 95\% CI, 2.954.70 ), and sorafenib (RR, 3.07; 95\% CI, 2.43-3.87) led to a remarkable increment in the risk for all-grade hypertensive events. Cabozantinib (RR, 9.17; 95\% CI, 1.24-67.77), regorafenib (RR, 7.81; 95\% CI, 3.06-19.94), cediranib (RR, 6.13; 95\% CI, 3.43-10.97), vandetanib (RR, 5.85; 95\% CI, 3.36-10.20), pazopanib (RR, 5.06; 95\% CI, 3.557.22), sunitinib (RR, 4.35; 95\% CI, 3.12-6.07), axitinib (RR, 4.22; 95\% CI, 1.75-10.16), and sorafenib (RR, $3.66 ; 95 \%$ CI, 2.89-4.63) also increased the probability of high-grade hypertensive events. The probability of hypertensive cases associated with VEGFR-TKIs varied significantly among individuals receiving varying types of VEGFR-TKI; this may be because different VEGFRTKIs target different receptors. Another potential hazard is probably simultaneous treatment with VEGFR-TKIs and other drugs. Our analysis demonstrated that an increased RR of high-grade and all-grade hypertensive events was significantly associated with both VEGFR-TKI monotherapy and combination therapy.

The VEGF pathway has an essential role in multiple physiological processes, including vascular and cardiomyocyte homeostasis, tissue neovascularization, and wound healing [96-98]. The mechanisms by which VEGFR-TKIs elevates BP remain uncertain. Evidence implies that the effects may be related directly to inhibition of the VEGF receptor. Such effects may include 1) impairment of angiogenesis, which reduces microvessel density (rarefaction); 2) production of molecules in response to hypoxia, which leads to an increase in vascular tone; 3) endothelial cell dysfunction, which leads to increased peripheral resistance; and 4) alterations in neurohormonal factors or the rennin-angiotensinaldosterone system [99, 100]. Nevertheless, few studies have explored the potential mechanisms underlying hypertension related to VEGFR-TKIs. Therefore, future studies centered around these specific issues are needed.

Although VEGFR-TKI-induced hypertension is a common adverse effect noticed by oncologists and cardiovascular medicine specialists, the deterrence and supervision of cardiovascular toxic effects remain controversial. Based on the guidelines of the NCI [101], the goal BP for individuals accepting anti-VEGF therapy is less than 140/90 mm Hg. For some patients at high risk of cardiovascular complications, targets should be revised downward. Before anti-VEGF therapy, BP should be well-controlled for more than 1 week. NCI clinical trial protocols advise that $\mathrm{BP}$ be monitored on a weekly basis in the time of the first cycle of antiVEGF therapy, following by at least every two to three weeks throughout treatment. If stage 1 hypertension ( $\geq 140 / 90 \mathrm{~mm} \mathrm{Hg}$ ) occurs or diastolic pressure increases by $20 \mathrm{~mm} \mathrm{Hg}$ from baseline during treatment, then antihypertensive therapy is required, the dose of current anti-hypertensive drugs should be adjusted, or new antihypertensive drugs should be added to ensure better control. Many drugs can be used to treat hypertension caused by VEGFR-TKIs. Non-dihydropyridine calciumchannel antagonists like diltiazem and verapamil are cytochrome P4503A4 (CYP3A4) inhibitors. Other drugs include dihydropyridines like nifedipine and amlodipine. Alternatively, ACEI or ARB are reasonable choices; these drugs have the added merits of enhancing endothelial function and microvessel density. Besides, antihypertensive medications like alpha blockers, diuretics and beta blockers, can also be utilized to control hypertension caused by VEGFR-TKIs [101, 102]. However, it is unclear whether any one agent is superior to another. When determining the type of antihypertensive medication to be utilized for a patient, the individual's medical condition and health status should be taken into consideration.

Despite our efforts to minimize the effects of confounding variables, there are several limitations that need to be considered. First, the incorporated trials were performed by different researchers from various institutions; thus the reported incidence of hypertensive events may suffer from potential bias. Also, the varying types of tumors and various VEGFR-TKIs examined might enhance heterogeneity. Moreover, the side effects often times will depend on the specific type of tumor in question. One such example includes RCC patients with 
nephrectomy and/or renal dysfunction who were more vulnerable to hypertension after treatment of VEGFRTKIs. Second, we examined a diverse population of individuals receiving VEGFR-TKI monotherapy or VEGFR-TKI-based combination therapy. Therefore, the design of the treatment in all arms was not exactly the same; moreover, the completeness of follow-up might lead to the root of heterogeneity. Third, pre-existing hypertension that have been controlled was more likely to influence the occurrence of hypertensive events during treatment, although patients with uncontrolled hypertension are generally excluded from VEGFR-TKI trials. Thus, the incidence and risk of hypertension might have been overestimated in our analysis. Therefore, in order to clarify this issue more trials are needed. Finally, our analysis was based on clinical trial levels rather than on individual patient data; therefore, confounding variables (e.g., comorbidities) were not included. Nevertheless, the trials incorporated in our analysis were high quality; some studies suggest that there are no significant differences between meta-analyses carried out at the trial level or individual level [103].

In summary, our RCTs investigation revealed the usage of VEGFR-TKIs is related to an enhanced occurrence of high-grade and all-grade hypertensive cases. Also, the probability of hypertension varies in line with tumor type and the type of VEGFR-TKI used. This information will assist physicians with recognizing the probability of hypertension related to VEGFR-TKIs and will help to tailor both dose and schedule to suit individual patients.

\section{MATERIALS AND METHODS}

\section{Data sources}

Publications from PubMed (January 1, 1966, to February 29, 2016) were reviewed. The search method is composed of the following items: sorafenib, BAY 439006, nexavar, AZD2171, sutent, SU11248, votrient, sunitinib, GW786034, vandetanib, ZD6474, caprelsa, dovitinib, nintedanib, ZD6474, axitinib, cediranib, regorafenib, BAY 73-4506, linifanib, ABT-869, motesanib, AMG 706, pazopanib, AG-013736, cabozantinib, cancer, and hypertension. Randomized, prospective, and controlled clinical trials composed the analysis. Key words such as hypertension, angiogenesis inhibitors, and VEGF were used to identify related papers. Additionally, objective searches of EMBASE (data from June 26, 1980 to February 29, 2016) and the Cochrane library were performed to guarnatee that no applicable clinical trial were ignored. Meanwhile, the website http://www. ClinicalTrials.gov was investigated in order to obtain more relevant registered research. Finally, trials reported at ASCO (http://asco.org/ASCO) and ESMO (http://www. esmo.org/ESMO) from 2001 to 2015 were also examined. If duplicate trials were identified, the latest trials with more detailed data were included.

\section{Quality assessment and data extraction}

The quality of each eligible study was assed using the five-point Jadad ranking system: a score of three or above in a trial was esteemed as high quality [13]. Data extraction was performed impartially by two researchers (BL and FD), and any differences were decided based on discussion. The required information was isolated from all of the studies. To ensure clinical significance, the trials in Phase I were not included in the study due to dose disparities in the data and small sample sizes. The selection criteria were as follows: (1) Phase II and Phase III RCTs involving cancer patients; (2) cancer patients had received VEGFR-TKIs or control treatments (placebo, current chemotherapy, best supportive care, and care standard); and (3) safety data with respect to hypertension events and sample sizes were available.

\section{Clinical endpoints}

The safety profile of each trial were analyzed, where clinical endpoints were selected. Events caused by hypertension were recorded in line with National Cancer Institute (NCI) CTCAE 2.0 or 3.0 (ctep.cancer.gov); both versions are identical with respect to the grading of hypertension (which starts at grade 1) (Supplementary Table S1).

\section{Statistical analysis}

We utilized Stata version 12.0 (Stata Corporation, College Station, TX) to analyze the data. To calculate the overall incidence of hypertensive events, the quantity of patients with high-grade and all-grade hypertensive events and the quantity of patients exposed to VEGFR-TKIs were abstracted. The the $95 \%$ confidence interval (CI) for allgrade and high-grade hypertensive patients and relative risk (RR) were then computed. Half-integer continuity correction was used if zero events were reported in the arm [14]. Statistical heterogeneity between trials was evaluated utilizing the $\chi^{2}$ test [15]. Heterogeneity was esteemed statistically significant when $\mathrm{P}_{\text {heterogeneity }}<0.1$. A fixedeffects or random-effects model was utilized according to whether heterogeneity existed or not. $P$ values $<0.05$ (twotailed) were considered significant. Subgroup evaluation was performed when heterogeneity existed. Sensitivity was analysed to test the stability of the obtained data, and we utilized Egger's test to evaluate publication bias. 


\section{Trial sequential analyses}

Trial sequential analyses (TSAs) were conducted to measure the possibility of type I error and to help evaluate the need for expanding the sample size. If zero events were reported in the trials, an additional 0.5 event was included in the arms. Two-sided tests were used, and a type I error was put at $5 \%$ and power at about $80 \%$. The incidence of all-grade and high-grade hypertensive events in the control experiment was put at $3.7 \%$ and $0.3 \%$, respectively. TSA was conducted using TSA V.0.9 $\beta$ (please visit www.ctu. $\mathrm{dk} / \mathrm{tsa} /$ ).

\section{ACKNOWLEDGMENTS}

This work was supported by the Program for Innovative Research Team at Chongqing University, 2013.

\section{CONFLICTS OF INTEREST}

The authors have no conflicts of interest to declare.

\section{REFERENCES}

1. Cook AM, Lesterhuis WJ, Nowak AK, and Lake RA. Chemotherapy and immunotherapy: mapping the road ahead. Curr Opin Immunol. 2016; 39: 23-9.

2. Polimeni $\mathrm{M}$, and Gazzano E. Is redox signaling a feasible target for overcoming multidrug resistance in cancer chemotherapy. Front Pharmacol. 2014; 5: 286.

3. Folkman J. Role of angiogenesis in tumor growth and metastasis. Semin Oncol. 2002; 29: 15-8.

4. Zetter BR. Angiogenesis and tumor metastasis. Annu Rev Med. 1998; 49: 407-24.

5. Sharp A, Bhosle J, Abdelraouf F, Popat S, O'Brien M, and Yap TA. Development of molecularly targeted agents and immunotherapies in small cell lung cancer. Eur J Cancer. 2016; 60: 26-39.

6. Hurwitz H, Fehrenbacher L, Novotny W, Cartwright T, Hainsworth J, Heim W, Berlin J, Baron A, Griffing S, and Holmgren E. Bevacizumab plus irinotecan, fluorouracil, and leucovorin for metastatic colorectal cancer. N Engl J Med. 2004; 350: 2335-42.

7. Fuchs CS, Tomasek J, Yong CJ, Dumitru F, Passalacqua R, Goswami C, Safran H, dos Santos LV, Aprile G, and Ferry DR. Ramucirumab monotherapy for previously treated advanced gastric or gastro-oesophageal junction adenocarcinoma (REGARD): an international, randomised, multicentre, placebo-controlled, phase 3 trial. The Lancet. 2014; 383: 31-9.

8. Van Cutsem E, Tabernero J, Lakomy R, Prenen H, Prausová J, Macarulla T, Ruff P, van Hazel GA, Moiseyenko V, and Ferry D. Addition of aflibercept to fluorouracil, leucovorin, and irinotecan improves survival in a phase III randomized trial in patients with metastatic colorectal cancer previously treated with an oxaliplatin-based regimen. J Clin Oncol. 2012 : JCO. 2012.42. 8201.

9. Jayson GC, Kerbel R, Ellis LM, and Harris AL. Antiangiogenic therapy in oncology: current status and future directions. The Lancet. 2016 .

10. Jang S, Zheng C, Tsai H, Fu AZ, Barac A, Atkins MB, Freedman AN, Minasian L, and Potosky AL. Cardiovascular toxicity after antiangiogenic therapy in persons older than 65 years with advanced renal cell carcinoma. Cancer. 2016; 122: 124-30.

11. Wu S, Chen JJ, Kudelka A, Lu J, and Zhu X. Incidence and risk of hypertension with sorafenib in patients with cancer: a systematic review and meta-analysis. The lancet oncology. 2008; 9: 117-23.

12. Tlemsani C, Mir O, Boudou-Rouquette P, Huillard O, Maley K, Ropert S, Coriat R, and Goldwasser F. Posterior reversible encephalopathy syndrome induced by anti-VEGF agents. Target Oncol. 2011; 6: 253-8.

13. Moher D, Jones A, Cook DJ, Jadad AR, Moher M, Tugwell $\mathrm{P}$, and Klassen TP. Does quality of reports of randomised trials affect estimates of intervention efficacy reported in meta-analyses. The Lancet. 1998; 352: 609-13.

14. Choueiri TK, Schutz FAB, Je Y, Rosenberg JE, and Bellmunt J. Risk of arterial thromboembolic events with sunitinib and sorafenib: a systematic review and metaanalysis of clinical trials. J Clin Oncol. 2010; 28: 2280-5.

15. Zintzaras E, and Ioannidis J. Heterogeneity testing in metaanalysis of genome searches. Genet Epidemiol. 2005; 28: 123-37.

16. Moher D, Liberati A, Tetzlaff J, and Altman DG. Preferred reporting items for systematic reviews and meta-analyses: the PRISMA statement. Ann Intern Med. 2009; 151: 264-9.

17. Heymach JV, Johnson BE, Prager D, Csada E, Roubec J, Pešek M, Špásová I, Belani CP, Bodrogi I, and Gadgeel S. Randomized, placebo-controlled phase II study of vandetanib plus docetaxel in previously treated non-smallcell lung cancer. J Clin Oncol. 2007; 25: 4270-7.

18. Heymach JV, Paz-Ares L, De Braud F, Sebastian M, Stewart DJ, Eberhardt WEE, Ranade AA, Cohen G, Trigo JM, and Sandler AB. Randomized phase II study of vandetanib alone or with paclitaxel and carboplatin as firstline treatment for advanced non-small-cell lung cancer. J Clin Oncol. 2008; 26: 5407-15.

19. Natale RB, Bodkin D, Govindan R, Sleckman BG, Rizvi NA, Capó A, Germonpré P, Eberhardt WEE, Stockman PK, and Kennedy SJ. Vandetanib versus gefitinib in patients with advanced non-small-cell lung cancer: results from a two-part, double-blind, randomized phase II study. J Clin Oncol. 2009; 27: 2523-9.

20. Herbst RS, Sun Y, Eberhardt WEE, Germonpré P, Saijo N, Zhou C, Wang J, Li L, Kabbinavar F, and Ichinose Y. Vandetanib plus docetaxel versus docetaxel as second-line treatment for patients with advanced non-small-cell lung 
cancer (ZODIAC): a double-blind, randomised, phase 3 trial. The lancet oncology. 2010; 11: 619-26.

21. Scagliotti G, Novello S, von Pawel J, Reck M, Pereira JR, Thomas M, Miziara JEA, Balint B, De Marinis F, and Keller A. Phase III study of carboplatin and paclitaxel alone or with sorafenib in advanced non-small-cell lung cancer. J Clin Oncol. 2010; 28: 1835-42.

22. Goss GD, Arnold A, Shepherd FA, Dediu M, Ciuleanu T, Fenton D, Zukin M, Walde D, Laberge F, and Vincent MD. Randomized, double-blind trial of carboplatin and paclitaxel with either daily oral cediranib or placebo in advanced nonsmall-cell lung cancer: NCIC Clinical Trials Group BR24 study. J Clin Oncol. 2010; 28: 49-55.

23. de Boer RH, Arrieta Ó, Yang C, Gottfried M, Chan V, Raats J, de Marinis F, Abratt RP, Wolf J, and Blackhall FH. Vandetanib plus pemetrexed for the second-line treatment of advanced non-small-cell lung cancer: A randomized, double-blind phase III trial. J Clin Oncol. 2011; 29: 106774.

24. Natale RB, Thongprasert S, Greco FA, Thomas M, Tsai C, Sunpaweravong P, Ferry D, Mulatero C, Whorf R, and Thompson J. Phase III trial of vandetanib compared with erlotinib in patients with previously treated advanced nonsmall-cell lung cancer. J Clin Oncol. 2011; 29: 1059-66.

25. Spigel DR, Burris HA, Greco FA, Shipley DL, Friedman EK, Waterhouse DM, Whorf RC, Mitchell RB, Daniel DB, and Zangmeister J. Randomized, double-blind, placebocontrolled, phase II trial of sorafenib and erlotinib or erlotinib alone in previously treated advanced non-smallcell lung cancer. J Clin Oncol. 2011; 29: 2582-9.

26. Scagliotti GV, Krzakowski M, Szczesna A, Strausz J, Makhson A, Reck M, Wierzbicki RF, Albert I, Thomas M, and Miziara JEA. Sunitinib plus erlotinib versus placebo plus erlotinib in patients with previously treated advanced non-small-cell lung cancer: A phase III trial. J Clin Oncol. 2012 : JCO. 2011.39. 2993.

27. Scagliotti GV, Vynnychenko I, Park K, Ichinose Y, Kubota K, Blackhall F, Pirker R, Galiulin R, Ciuleanu T, and Sydorenko O. International, randomized, placebocontrolled, double-blind phase III study of motesanib plus carboplatin/paclitaxel in patients with advanced nonsquamous non-small-cell lung cancer: MONET1. J Clin Oncol. 2012; 30: 2829-36.

28. Paz-Ares LG, Biesma B, Heigener D, von Pawel J, Eisen T, Bennouna J, Zhang L, Liao M, Sun Y, and Gans S. Phase III, randomized, double-blind, placebo-controlled trial of gemcitabine/cisplatin alone or with sorafenib for the firstline treatment of advanced, nonsquamous non-small-cell lung cancer. J Clin Oncol. 2012; 30: 3084-92.

29. Lee JS, Hirsh V, Park K, Qin S, Blajman CR, Perng R, Chen Y, Emerson L, Langmuir P, and Manegold C. Vandetanib versus placebo in patients with advanced non-small-cell lung cancer after prior therapy with an epidermal growth factor receptor tyrosine kinase inhibitor: A randomized, double-blind phase III trial (ZEPHYR). J Clin Oncol. 2012; 30: 1114-21.

30. Ahn JS, Lee KH, Sun JM, Park K, Kang ES, Cho EK, Lee DH, Kim SW, Lee GW, Kang JH, Lee JS, Lee JW, and Ahn MJ. A randomized, phase II study of vandetanib maintenance for advanced or metastatic non-small-cell lung cancer following first-line platinum-doublet chemotherapy. Lung Cancer. 2013; 82: 455-60.

31. Heist RS, Wang X, Hodgson L, Otterson GA, Stinchcombe TE, Gandhi L, Villalona-Calero MA, Watson P, Vokes EE, and Socinski MA. CALGB 30704 (alliance): a randomized phase II study to assess the efficacy of pemetrexed or sunitinib or pemetrexed plus sunitinib in the second-line treatment of advanced non-small-cell lung cancer. J Thorac Oncol. 2014; 9: 214-21.

32. Laurie SA, Solomon BJ, Seymour L, Ellis PM, Goss GD, Shepherd FA, Boyer MJ, Arnold AM, Clingan P, and Laberge F. Randomised, double-blind trial of carboplatin and paclitaxel with daily oral cediranib or placebo in patients with advanced non-small cell lung cancer: NCIC Clinical Trials Group study BR29. Eur J Cancer. 2014; 50: 706-12.

33. Gridelli C, Novello S, Zilembo N, Luciani A, Favaretto AG, De Marinis F, Genestreti G, Crinò L, Grossi F, and Caffo O. Phase II Randomized Study of Vandetanib Plus Gemcitabine or Gemcitabine Plus Placebo as First-Line Treatment of Advanced Non-Small-Cell Lung Cancer in Elderly Patients. J Thorac Oncol. 2014; 9: 733-7.

34. Paz-Ares L, Hirsh V, Zhang L, de Marinis F, Yang JC, Wakelee HA, Seto T, Wu Y, Novello S, and Juhász E. Monotherapy Administration of Sorafenib in Patients With Non-Small Cell Lung Cancer (MISSION) Trial: A Phase III, Multicenter, Placebo-Controlled Trial of Sorafenib in Patients with Relapsed or Refractory Predominantly Nonsquamous Non-Small-Cell Lung Cancer after 2 or 3 Previous Treatment Regimens. J Thorac Oncol. 2015; 10: 1745-53.

35. Barrios CH, Liu M, Lee SC, Vanlemmens L, Ferrero J, Tabei T, Pivot X, Iwata H, Aogi K, and Lugo-Quintana R. Phase III randomized trial of sunitinib versus capecitabine in patients with previously treated HER2-negative advanced breast cancer. Breast Cancer Res Treat. 2010; 121: 121-31.

36. Wildiers H, Fontaine C, Vuylsteke P, Martens M, Canon JL, Wynendaele W, Focan C, De Greve J, Squifflet $\mathrm{P}$, and Paridaens R. Multicenter phase II randomized trial evaluating antiangiogenic therapy with sunitinib as consolidation after objective response to taxane chemotherapy in women with HER2-negative metastatic breast cancer. Breast Cancer Res Treat. 2010; 123: 463-9.

37. Rugo HS, Stopeck AT, Joy AA, Chan S, Verma S, Lluch A, Liau KF, Kim S, Bycott P, and Rosbrook B. Randomized, placebo-controlled, double-blind, phase II study of axitinib plus docetaxel versus docetaxel plus placebo in patients with metastatic breast cancer. J Clin Oncol. 2011; 29: 245965. 
38. Bergh J, Bondarenko IM, Lichinitser MR, Liljegren A, Greil R, Voytko NL, Makhson AN, Cortes J, Lortholary A, and Bischoff J. First-line treatment of advanced breast cancer with sunitinib in combination with docetaxel versus docetaxel alone: results of a prospective, randomized phase III study. J Clin Oncol. 2012 : JCO. 2011.35. 7376.

39. Baselga J, Segalla JGM, Roché H, del Giglio A, Pinczowski H, Ciruelos EM, Cabral Filho S, Gómez P, Van Eyll B, and Bermejo B. Sorafenib in combination with capecitabine: an oral regimen for patients with HER2-negative locally advanced or metastatic breast cancer. J Clin Oncol. 2012; 30: 1484-91.

40. Schwartzberg LS, Tauer KW, Hermann RC, MakariJudson G, Isaacs C, Beck JT, Kaklamani V, Stepanski EJ, Rugo HS, and Wang W. Sorafenib or Placebo with Either Gemcitabine or Capecitabine in Patients with HER-2Negative Advanced Breast Cancer That Progressed during or after Bevacizumab. Clin Cancer Res. 2013; 19: 2745-54.

41. Crown JP, Diéras V, Staroslawska E, Yardley DA, Bachelot T, Davidson N, Wildiers H, Fasching PA, Capitain O, and Ramos M. Phase III trial of sunitinib in combination with capecitabine versus capecitabine monotherapy for the treatment of patients with pretreated metastatic breast cancer. J Clin Oncol. 2013 : JCO. 2012.43. 3391.

42. Johnston SRD, Gómez H, Stemmer SM, Richie M, Durante M, Pandite L, Goodman V, and Slamon D. A randomized and open-label trial evaluating the addition of pazopanib to lapatinib as first-line therapy in patients with HER2-positive advanced breast cancer. Breast Cancer Res Treat. 2013; 137: 755-66.

43. Curigliano G, Pivot X, Cortés J, Elias A, Cesari R, Khosravan R, Collier M, Huang X, Cataruozolo PE, and Kern KA. Randomized phase II study of sunitinib versus standard of care for patients with previously treated advanced triple-negative breast cancer. The Breast. 2013; 22: 650-6.

44. Llovet JM, Ricci S, Mazzaferro V, Hilgard P, Gane E, Blanc J, de Oliveira AC, Santoro A, Raoul J, and Forner A. Sorafenib in advanced hepatocellular carcinoma. N Engl J Med. 2008; 359: 378-90.

45. Cheng A, Kang Y, Chen Z, Tsao C, Qin S, Kim JS, Luo R, Feng J, Ye S, and Yang T. Efficacy and safety of sorafenib in patients in the Asia-Pacific region with advanced hepatocellular carcinoma: a phase III randomised, doubleblind, placebo-controlled trial. The lancet oncology. 2009; 10: 25-34.

46. Abou-Alfa GK, Johnson P, Knox JJ, Capanu M, Davidenko I, Lacava J, Leung T, Gansukh B, and Saltz LB. Doxorubicin plus sorafenib vs doxorubicin alone in patients with advanced hepatocellular carcinoma: a randomized trial. JAMA. 2010; 304: 2154-60.

47. Kudo M, Imanaka K, Chida N, Nakachi K, Tak W, Takayama T, Yoon J, Hori T, Kumada H, and Hayashi N. Phase III study of sorafenib after transarterial chemoembolisation in Japanese and Korean patients with unresectable hepatocellular carcinoma. Eur J Cancer. 2011; 47: 2117-27.

48. Hsu C, Yang T, Huo T, Hsieh R, Yu C, Hwang W, Hsieh T, Huang W, Chao Y, and Meng R. Vandetanib in patients with inoperable hepatocellular carcinoma: a phase II, randomized, double-blind, placebo-controlled study. J Hepatol. 2012; 56: 1097-103.

49. Bruix J, Takayama T, Mazzaferro V, Chau G, Yang J, Kudo M, Cai J, Poon RT, Han K, and Tak WY. Adjuvant sorafenib for hepatocellular carcinoma after resection or ablation (STORM): a phase 3, randomised, double-blind, placebo-controlled trial. The Lancet Oncology. 2015; 16: 1344-54.

50. Lencioni R, Llovet JM, Han G, Tak WY, Yang J, Guglielmi A, Paik SW, Reig M, Chau G, and Luca A. Sorafenib or Placebo plus TACE with Doxorubicin-Eluting Beads for Intermediate-Stage HCC: Phase II, Randomized, DoubleBlind SPACE Trial. J Hepatol. 2016 .

51. Escudier B, Eisen T, Stadler WM, Szczylik C, Oudard S, Siebels M, Negrier S, Chevreau C, Solska E, and Desai AA. Sorafenib in advanced clear-cell renal-cell carcinoma. N Engl J Med. 2007; 356: 125-34.

52. Motzer RJ, Hutson TE, Tomczak P, Michaelson MD, Bukowski RM, Rixe O, Oudard S, Negrier S, Szczylik C, and Kim ST. Sunitinib versus interferon alfa in metastatic renal-cell carcinoma. N Engl J Med. 2007; 356: 115-24.

53. Sternberg CN, Davis ID, Mardiak J, Szczylik C, Lee E, Wagstaff J, Barrios CH, Salman P, Gladkov OA, and Kavina A. Pazopanib in locally advanced or metastatic renal cell carcinoma: results of a randomized phase III trial. J Clin Oncol. 2010; 28: 1061-8.

54. Mulders P, Hawkins R, Nathan P, de Jong I, Osanto S, Porfiri E, Protheroe A, van Herpen CML, Mookerjee B, and Pike L. Cediranib monotherapy in patients with advanced renal cell carcinoma: results of a randomised phase II study. Eur J Cancer. 2012; 48: 527-37.

55. Haas NB, Manola J, Uzzo RG, Flaherty KT, Wood CG, Kane C, Jewett M, Dutcher JP, Atkins MB, and Pins M. Adjuvant sunitinib or sorafenib for high-risk, nonmetastatic renal-cell carcinoma (ECOG-ACRIN E2805): a double-blind, placebo-controlled, randomised, phase 3 trial. The Lancet. 2016 .

56. Leboulleux S, Bastholt L, Krause T, de la Fouchardiere C, Tennvall J, Awada A, Gómez JM, Bonichon F, Leenhardt L, and Soufflet C. Vandetanib in locally advanced or metastatic differentiated thyroid cancer: a randomised, double-blind, phase 2 trial. The lancet oncology. 2012; 13: 897-905.

57. Wells SA, Robinson BG, Gagel RF, Dralle H, Fagin JA, Santoro M, Baudin E, Elisei R, Jarzab B, and Vasselli JR. Vandetanib in patients with locally advanced or metastatic medullary thyroid cancer: a randomized, double-blind phase III trial. J Clin Oncol. 2012; 30: 134-41. 
58. Elisei R, Schlumberger MJ, Müller SP, Schöffski P, Brose MS, Shah MH, Licitra L, Jarzab B, Medvedev V, and Kreissl MC. Cabozantinib in progressive medullary thyroid cancer. J Clin Oncol. 2013; 31: 3639-46.

59. Brose MS, Nutting CM, Jarzab B, Elisei R, Siena S, Bastholt L, de la Fouchardiere C, Pacini F, Paschke R, and KeeShong Y. Sorafenib in locally advanced or metastatic, radioactive iodine-refractory, differentiated thyroid cancer: a randomized, double-blind, phase 3 trial. Lancet. 2014; 384: 319.

60. Spano J, Chodkiewicz C, Maurel J, Wong R, Wasan H, Barone C, Létourneau R, Bajetta E, Pithavala Y, and Bycott P. Efficacy of gemcitabine plus axitinib compared with gemcitabine alone in patients with advanced pancreatic cancer: an open-label randomised phase II study. The Lancet. 2008; 371: 2101-8.

61. Kindler HL, Ioka T, Richel DJ, Bennouna J, Létourneau R, Okusaka T, Funakoshi A, Furuse J, Park YS, and Ohkawa S. Axitinib plus gemcitabine versus placebo plus gemcitabine in patients with advanced pancreatic adenocarcinoma: a double-blind randomised phase 3 study. The lancet oncology. 2011; 12: 256-62.

62. Gonçalves A, Gilabert M, François E, Dahan L, Perrier H, Lamy R, Re D, Largillier R, Gasmi M, and Tchiknavorian $\mathrm{X}$. BAYPAN study: a double-blind phase III randomized trial comparing gemcitabine plus sorafenib and gemcitabine plus placebo in patients with advanced pancreatic cancer. Ann Oncol. 2012; 23: 2799-805.

63. Reni M, Cereda S, Milella M, Novarino A, Passardi A, Mambrini A, Di Lucca G, Aprile G, Belli C, and Danova M. Maintenance sunitinib or observation in metastatic pancreatic adenocarcinoma: a phase II randomised trial. Eur J Cancer. 2013; 49: 3609-15.

64. Hoff PM, Hochhaus A, Pestalozzi BC, Tebbutt NC, Li J, Kim TW, Koynov KD, Kurteva G, Pintér T, and Cheng Y. Cediranib plus FOLFOX/CAPOX versus placebo plus FOLFOX/CAPOX in patients with previously untreated metastatic colorectal cancer: a randomized, double-blind, phase III study (HORIZON II). J Clin Oncol. 2012; 30: 3596-603.

65. Grothey A, Van Cutsem E, Sobrero A, Siena S, Falcone A, Ychou M, Humblet Y, Bouché O, Mineur L, and Barone C. Regorafenib monotherapy for previously treated metastatic colorectal cancer (CORRECT): an international, multicentre, randomised, placebo-controlled, phase 3 trial. The Lancet. 2013; 381: 303-12.

66. Tabernero J, Garcia-Carbonero R, Cassidy J, Sobrero A, Van Cutsem E, Köhne C, Tejpar S, Gladkov O, Davidenko I, and Salazar R. Sorafenib in combination with oxaliplatin, leucovorin, and fluorouracil (modified FOLFOX6) as first-line treatment of metastatic colorectal cancer: the RESPECT trial. Clin Cancer Res. 2013; 19: 2541-50.

67. Carrato A, Swieboda-Sadlej A, Staszewska-Skurczynska M, Lim R, Roman L, Shparyk Y, Bondarenko I, Jonker DJ, Sun $\mathrm{Y}$, and Jhony A. Fluorouracil, leucovorin, and irinotecan plus either sunitinib or placebo in metastatic colorectal cancer: a randomized, phase III trial. J Clin Oncol. 2013 : JCO. 2012.45. 1930.

68. Herzog TJ, Scambia G, Kim B, Lhommé C, Markowska J, Ray-Coquard I, Sehouli J, Colombo N, Shan M, and Petrenciuc O. A randomized phase II trial of maintenance therapy with Sorafenib in front-line ovarian carcinoma. Gynecol Oncol. 2013; 130: 25-30.

69. du Bois A, Floquet A, Kim J, Rau J, Del Campo JM, Friedlander M, Pignata S, Fujiwara K, Vergote I, and Colombo N. Incorporation of pazopanib in maintenance therapy of ovarian cancer. J Clin Oncol. 2014; 32: 3374-82.

70. Pignata S, Lorusso D, Scambia G, Sambataro D, Tamberi S, Cinieri S, Mosconi AM, Orditura M, Brandes AA, and Arcangeli V. Pazopanib plus weekly paclitaxel versus weekly paclitaxel alone for platinum-resistant or platinum-refractory advanced ovarian cancer (MITO 11): a randomised, open-label, phase 2 trial. The Lancet Oncology. 2015; 16: 561-8.

71. Hainsworth JD, Thompson DS, Bismayer JA, Gian VG, Merritt WM, Whorf RC, Finney LH, and Dudley BS. Paclitaxel/carboplatin with or without sorafenib in the firstline treatment of patients with stage III/IV epithelial ovarian cancer: a randomized phase II study of the Sarah Cannon Research Institute. Cancer Med. 2015; 4: 673-81.

72. Demetri GD, Garrett CR, Schöffski P, Shah MH, Verweij J, Leyvraz S, Hurwitz HI, Pousa AL, Le Cesne A, and Goldstein D. Complete longitudinal analyses of the randomized, placebo-controlled, phase III trial of sunitinib in patients with gastrointestinal stromal tumor following imatinib failure. Clin Cancer Res. 2012; 18: 3170-9.

73. Demetri GD, Reichardt P, Kang Y, Blay J, Rutkowski P, Gelderblom H, Hohenberger P, Leahy M, von Mehren $\mathrm{M}$, and Joensuu H. Efficacy and safety of regorafenib for advanced gastrointestinal stromal tumours after failure of imatinib and sunitinib (GRID): an international, multicentre, randomised, placebo-controlled, phase 3 trial. The Lancet. 2013; 381: 295-302.

74. Komatsu Y, Doi T, Sawaki A, Kanda T, Yamada Y, Kuss I, Demetri GD, and Nishida T. Regorafenib for advanced gastrointestinal stromal tumors following imatinib and sunitinib treatment: a subgroup analysis evaluating Japanese patients in the phase III GRID trial. Int J Clin Oncol. 2015; 20: 905-12.

75. Limaye S, Riley S, Zhao S, O’Neill A, Posner M, Adkins D, Jaffa Z, Clark J, and Haddad R. A randomized phase II study of docetaxel with or without vandetanib in recurrent or metastatic squamous cell carcinoma of head and neck (SCCHN). Oral Oncol. 2013; 49: 835-41.

76. Gilbert J, Schell MJ, Zhao X, Murphy B, Tanvetyanon T, Leon ME, Hayes DN, Haigentz M, Saba N, and Nieva J. A randomized phase II efficacy and correlative studies of cetuximab with or without sorafenib in recurrent and/or metastatic head and neck squamous cell carcinoma. Oral Oncol. 2015; 51: 376-82. 
77. McDermott DF, Sosman JA, Gonzalez R, Hodi FS, Linette GP, Richards J, Jakub JW, Beeram M, Tarantolo S, and Agarwala S. Double-blind randomized phase II study of the combination of sorafenib and dacarbazine in patients with advanced melanoma: a report from the 11715 Study Group. J Clin Oncol. 2008; 26: 2178-85.

78. Horti J, Widmark A, Stenzl A, Federico MH, Abratt RP, Sanders N, Pover GM, and Bodrogi I. A randomized, double-blind, placebo-controlled phase II study of vandetanib plus docetaxel/prednisolone in patients with hormone-refractory prostate cancer. Cancer Biother Radiopharm. 2009; 24: 175-80.

79. Michaelson MD, Oudard S, Ou Y, Sengeløv L, Saad F, Houede N, Ostler P, Stenzl A, Daugaard G, and Jones R. Randomized, placebo-controlled, phase III trial of sunitinib plus prednisone versus prednisone alone in progressive, metastatic, castration-resistant prostate cancer. J Clin Oncol. 2014; 32: 76-82.

80. van der Graaf WTA, Blay J, Chawla SP, Kim D, BuiNguyen B, Casali PG, Schöffski P, Aglietta M, Staddon AP, and Beppu Y. Pazopanib for metastatic soft-tissue sarcoma (PALETTE): a randomised, double-blind, placebocontrolled phase 3 trial. The Lancet. 2012; 379: 1879-86.

81. Kawai A, Araki N, Hiraga H, Sugiura H, Matsumine A, Ozaki T, Ueda T, Ishii T, Esaki T, and Machida M. A randomized, double-blind, placebo-controlled, Phase III study of pazopanib in patients with soft tissue sarcoma: results from the Japanese subgroup. Jpn J Clin Oncol. 2016; 46: 248-53.

82. Arnold AM, Seymour L, Smylie M, Ding K, Ung Y, Findlay B, Lee CW, Djurfeldt M, Whitehead M, and Ellis P. Phase II study of vandetanib or placebo in small-cell lung cancer patients after complete or partial response to induction chemotherapy with or without radiation therapy: National Cancer Institute of Canada Clinical Trials Group Study BR. 20. J Clin Oncol. 2007; 25: 4278-84.

83. Raymond E, Dahan L, Raoul J, Bang Y, Borbath I, Lombard-Bohas C, Valle J, Metrakos P, Smith D, and Vinik A. Sunitinib malate for the treatment of pancreatic neuroendocrine tumors. N Engl J Med. 2011; 364: 501-13.

84. Krege S, Rexer H, Dorp F, Geeter P, Klotz T, Retz M, Heidenreich A, Kühn M, Kamradt J, and Feyerabend S. Prospective randomized double-blind multicentre phase II study comparing gemcitabine and cisplatin plus sorafenib chemotherapy with gemcitabine and cisplatin plus placebo in locally advanced and/or metastasized urothelial cancer: SUSE (AUO-AB 31/05). BJU Int. 2014; 113: 429-36.

85. Yi JH, Lee J, Park SH, Park JO, Yim DS, Park YS, Lim HY, and Kang WK. Randomised phase II trial of docetaxel and sunitinib in patients with metastatic gastric cancer who were previously treated with fluoropyrimidine and platinum. Br J Cancer. 2012; 106: 1469-74.

86. Röllig C, Serve H, Hüttmann A, Noppeney R, MüllerTidow C, Krug U, Baldus CD, Brandts CH, Kunzmann V, and Einsele H. Addition of sorafenib versus placebo to standard therapy in patients aged 60 years or younger with newly diagnosed acute myeloid leukaemia (SORAML): a multicentre, phase 2, randomised controlled trial. The Lancet Oncology. 2015; 16: 1691-9.

87. Santoro A, Gebbia V, Pressiani T, Testa A, Personeni N, Bajardi EA, Foa P, Buonadonna A, Bencardino K, and Barone C. A randomized, multicenter, phase II study of vandetanib monotherapy versus vandetanib in combination with gemcitabine versus gemcitabine plus placebo in subjects with advanced biliary tract cancer: the VanGogh study. Ann Oncol. 2015; 26: 542-7.

88. Willi C, Bodenmann P, Ghali WA, Faris PD, and Cornuz J. Active smoking and the risk of type 2 diabetes: a systematic review and meta-analysis. JAMA. 2007; 298: 2654-64.

89. Folkman J. Angiogenesis in cancer, vascular, rheumatoid and other disease. Nat Med. 1995; 1: 27-30.

90. Sherwood LM, Parris EE, and Folkman J. Tumor angiogenesis: therapeutic implications. N Engl J Med. 1971; 285: 1182-6.

91. An MM, Zou Z, Shen H, Liu P, Chen ML, Cao YB, and Jiang YY. Incidence and risk of significantly raised blood pressure in cancer patients treated with bevacizumab: an updated meta-analysis. Eur J Clin Pharmacol. 2010; 66: 813-21.

92. Flaherty KT, Lee SJ, Zhao F, Schuchter LM, Flaherty L, Kefford R, Atkins MB, Leming P, and Kirkwood JM. Phase III trial of carboplatin and paclitaxel with or without sorafenib in metastatic melanoma. J Clin Oncol. 2013; 31 : 373-9.

93. Sivendran S, Liu Z, Portas LJ, Yu M, Hahn N, Sonpavde G, Oh WK, and Galsky MD. Treatment-related mortality with vascular endothelial growth factor receptor tyrosine kinase inhibitor therapy in patients with advanced solid tumors: a meta-analysis. Cancer Treat Rev. 2012; 38: 919-25.

94. Punt CJ, Tol J, Rodenburg CJ, Cats A, Creemers GM, Schrama JG, Erdkamp FL, Vos A, Mol L, and Antonini NF. Randomized phase III study of capecitabine, oxaliplatin, and bevacizumab with or without cetuximab in advanced colorectal cancer (ACC), the CAIRO2 study of the Dutch Colorectal Cancer Group (DCCG). 2008; 26: LBA4011.

95. Pivot X, Schneeweiss A, Verma S, Thomssen C, PassosCoelho JL, Benedetti G, Ciruelos E, von Moos R, Chang $\mathrm{H}$, and Duenne A. Efficacy and safety of bevacizumab in combination with docetaxel for the first-line treatment of elderly patients with locally recurrent or metastatic breast cancer: results from AVADO. Eur J Cancer. 2011; 47: 2387-95.

96. Chen HX, and Cleck JN. Adverse effects of anticancer agents that target the VEGF pathway. Nat Rev Clin Oncol. 2009; 6: 465-77.

97. Mendlein J, and Furfine E. Vegf pathway blockade :Google Patents,2008.

98. Kieran MW, Kalluri R, and Cho Y. The VEGF pathway in cancer and disease: responses, resistance, and the path 
forward. Cold Spring Harb Perspect Med. 2012; 2: a006593.

99. Zhu X, Stergiopoulos K, and Wu S. Risk of hypertension and renal dysfunction with an angiogenesis inhibitor sunitinib: systematic review and meta-analysis. Acta Oncol. 2009; 48: 9-17.

100. Sica DA. Angiogenesis inhibitors and hypertension: an emerging issue. J Clin Oncol. 2006; 24: 1329-31.

101. Maitland ML, Bakris GL, Black HR, Chen HX, Durand J, Elliott WJ, Ivy SP, Leier CV, Lindenfeld J, and Liu G. Initial assessment, surveillance, and management of blood pressure in patients receiving vascular endothelial growth factor signaling pathway inhibitors. J Natl Cancer Inst. 2010
102. Rini BI, Quinn DI, Baum M, Wood LS, Tarazi J, Rosbrook B, Arruda LS, Cisar L, Roberts WG, and Kim $\mathrm{S}$. Hypertension among patients with renal cell carcinoma receiving axitinib or sorafenib: analysis from the randomized phase III AXIS trial. Target Oncol. 2015; 10: 45-53.

103. Bennett CL, Silver SM, Djulbegovic B, Samaras AT, Blau CA, Gleason KJ, Barnato SE, Elverman KM, Courtney DM, and McKoy JM. Venous thromboembolism and mortality associated with recombinant erythropoietin and darbepoetin administration for the treatment of cancer-associated anemia. JAMA. 2008; 299: 914-24. 